\title{
RESEARCH
}

Open Access

\section{What kind of innovations do we need to secure our future?}

\author{
Ulrich Witt ${ }^{1,2}$
}

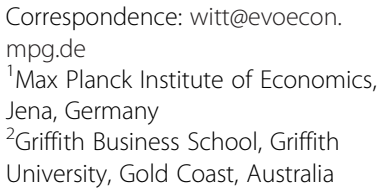

Correspondence: witt@evoecon. mpg.de

${ }^{1}$ Max Planck Institute of Economics, Jena, Germany

${ }^{2}$ Griffith Business School, Griffith University, Gold Coast, Australia

\begin{abstract}
The question of what kind of innovations can secure our future is in this paper put in perspective with the unknown risks which innovations may imply. Innovations sometimes turn out to cause severe negative externalities after they have successfully passed the market test. In such cases, the social costs that are revealed only later may result in substantial welfare losses. Obviously, innovations of this kind are the opposite of what is needed. Can the knowledge flows related to innovation processes be strategically arranged in such a way that these externality risks are minimized? The options to be reviewed relate to the debate on open vs. closed innovation processes initiated in management science. The paper briefly discusses several aspects of this debate and introduces a model of self-organizing belief formation which reflects the conditions of open vs. closed innovation processes. On this basis it is shown that a conflict arises between arrangements fostering an early discovery of negative externalities of innovations and the incentives potential innovators have to pursue innovative activities.
\end{abstract}

\section{Introduction}

It is generally acknowledged now how much economic and technological innovations have changed our life and will continue to do so. After their impact on the economy has fully been recognized, innovations have over the past decades become one of the most intensely researched topics in economics (see, e.g., (Cohen 2010)) and management science (Damanpour and Aravind 2012). The research that has been conducted covered three main themes. A first theme is the exploration of the very innovation process. How are innovations created and what strategic choices are there regarding the organization of innovation processes? A second theme relates to the motivational aspects of innovative activities. What particular knowledge-related incentive problems occur in their context and how do they depend on the specificities of the strategic organization of the innovation process? A third main research theme concerns the economic effects of innovations. What, precisely, are the consequences of successfully spreading innovations? How are markets, industries and society as a whole affected?

The last theme has been under special scrutiny in the Neo-Schumpeterian literature (see (Hanusch and Pyka 2007)). Following Schumpeter's portrayal of innovation competition as an engine of economic growth and prosperity, this literature highlights the positive effects of innovativeness. With new goods and services and labor productivity rising in the innovative firms and industries, the division of labor is constantly

(c) 2016 The Author(s). Open Access This article is distributed under the terms of the Creative Commons Attribution 4.0 International License (http://creativecommons.org/licenses/by/4.0/), which permits unrestricted use, distribution, and reproduction in any medium, provided you give appropriate credit to the original author(s) and the source, provide a link to the Creative Commons license, and indicate if changes were made. 
transformed both nationally and internationally (Metcalfe et al. 2006). An ability to stimulate domestic innovativeness makes initially less developed countries succeed in catching-up internationally with the more advanced economies (Fagerberg et al. 2007). By offering new employment opportunities and paying higher wages, innovative firms and industries allow national per capita income to grow, and thus to raise the living standard of the masses (as (Schumpeter 1942), Chap. 7 put it). In a similar spirit, the management literature dealing with the third research theme propagates innovative activities as a prime strategy for gaining a competitive advantage and generating sustained profits.

The criterion on which the positive assessment of innovativeness and its effects is based is that innovations successfully pass the market test. To do so, there must be a demand for the innovations. This can be the case because they offer a solution to problems not satisfactory solved before. In most cases, however, there is a demand for innovations simply because they result in a lower price, better quality, and/or more convenient purchasing conditions. If innovations successfully pass the market test this automatically means that the demand side is made better off. At the same time the innovator can earn a profit. For that reason innovations successfully passing the market test are usually thought to improve welfare and are therefore considered highly desirable.

Such a view is indeed warranted, as long as innovations do not cause any negative externalities, i.e. welfare diminishing effects which are not, or not fully, reflected by the price system. Yet, this often neglected proviso is far from always being satisfied. Innovations that turn out to trigger negative externalities are not exceptional. In fact, innovations can "bite back" (Tenner 1996) and cause substantial welfare losses, if their social costs turn out to exceed the private gains. Innovations of that kind are, of course, not those we need to secure our future.

The problem that a successful market test of goods and services does not guarantee a full internalization of the social costs they may cause is not specific to innovations. Even when harmful externalities are well known, affected third parties may be unable to force the party which causes the social costs to internalize these costs. (Government regulations such as safety, hygiene, and environmental norms which make violators liable for transgressions aim at curing this.) What is specific to innovations is that, because of the epistemic boundary implied by novelty, their negative effects are often completely unanticipated and hence not subject to existing regulations. The social costs of an innovation only turn out with a considerable time delay after it has spread in the market. Even if regulations or other measures are then invoked, substantial damages may have already accumulated. Hence, because of the epistemic boundary the risk of potentially very substantial welfare losses caused by non-internalized social costs of an innovation can never be excluded.

Therefore, the question of what kind of innovations we need to secure our future has to be put in perspective with the unknown risks which innovations may imply. Are there welfare enhancing innovation processes for which the externality risks could be minimized? Put more specifically in the context of the present paper, can innovationrelated knowledge flows be strategically arranged so that negative effects can as early as possible be discovered and accounted for? If so, how are the incentives for innovators affected by arrangements designed to reduce the risk? 
As will turn out, the attempt to answer these questions requires discussing several problems related to the other two main themes of research on innovations. The question of the arrangement of innovation-related knowledge flows refers to the details and specificities of the innovation process - the first of the research themes mentioned above. More in particular it will have to be discussed what role the open vs. closed innovation debate has to play in this context which was initiated in management science by Chesbrough (2003). The inquiry would be incomplete, however, if it would not also ask to what extent such measures are compatible with the incentives to innovate - the motivational issues dealt with under the second of the mentioned research themes.

The argumentation in the present paper proceeds as follows. To lay out the ground for addressing the question in the heading, Section 2 briefly recapitulates some key insights generated by the research on the first two main research themes just mentioned. Special attention will be given to the role of open vs. closed innovation processes and the motivational problems, or incentive problems, relevant for these processes. Section 3 then turns to the question of what determines whether and when innovations are successful and whether successful innovation are always also welfare improving. Related to the heading of this paper - asking what kind of innovations we need to secure our future - the problematic role of externalities and social costs will be highlighted which innovations can cause. Section 4 presents a simple model of open and closed innovation processes. The model is designed to explore what difference open vs. closed innovation processes make with respect to keeping the risk of undesirable innovations down and what motivational or incentive problems may turn up in this context. Section 5 presents the conclusions.

\section{Knowledge flows and incentive problems in innovation processes - a brief recap}

Knowledge flows related to innovative activities are a core component of the first major research theme dealing with the details and specificities of how innovations are being created and how the innovation process can best be organized. Whenever novelty comes into play, this research confronts a hard epistemic bound (see (Witt 2009) for a detailed discussion). Innovations mirror new cognitive concepts which emerge when inventors, researchers, developers, or entrepreneurs (re-) combine - often in team work - already existing cognitive concepts into something that can be given a novel meaning. How one arrives at identifying a new sense in combinations - the act of conceptual integration - is neither well understood nor, of course, predictable.

The following may serve as an example. At the end of the 19th century Herman Hollerith combined punch cards having holes in specific places - a device known from mechanic musical instruments - with the cognitive concept of coding numbers by the arrangement of holes on the cards. In mechanic musical instruments, this technique was used for coding musical notes. Air pressure passing through the holes of the punch cards triggered an acoustic tone in pipes, strings or bells associated with the holes. Hollerith not only replaced musical notes by numbers. He also combined his punch cards with an electric reading device replacing air pressure: spring-mounted needles made an electrical connection when passing through the holes. Taken in isolation, all of the elements which Hollerith combined were no new concepts, yet their combination was. In fact, it was the first electro-mechanically machine able to tabulate and 
sort numerical information automatically. This turned out to be a major innovation when introduced to the market by the Tabulating Machine Company, later Computer Tabulating Recording Company renamed IBM in 1924. (see (Kistermann 1991)).

In this case, as in the case of all innovations, the implications and consequences of the novel concepts were not brought out instantaneously. They were unraveled in a trial and error process which can last for years and regularly spurs further knowledge extensions. The role of knowledge flows for and in the revelation process becomes apparent by two questions: where do the concepts entering the new combinations come from and how permeable is the process of unraveling their implications? For these questions the distinction between open vs. closed innovation has come to be considered crucial (Chesbrough et al. 2006). Both open and closed innovations originate from the (re-) combining of pre-existing cognitive concepts by inventors, researchers, developers, entrepreneurs, or a team of them. In both cases, access to knowledge which these actors have not created themselves but absorbed from their social and cultural environment - is crucial. It is therefore not the source of knowledge as such that makes the difference between open and closed innovations. It is rather the strategic choice of the way in which the acquisition of relevant outside knowledge takes place and the extent to which it is also involving outbound information flows.

In innovation processes open to inbound knowledge flows, commercial firms or other organizations follow a strategy of tapping relevant external knowledge on purpose. They can do so in informal ways and/or formally by, e.g., contracting external expertise or implementing crowd sourcing arrangements. These inbound knowledge flows may be combined with outbound knowledge flows, e.g., in a mutual trade of information. ${ }^{1}$ The more the acquisition of on purpose, innovation-related knowledge from outside actors is made part of the strategic organizational design, of explicit legal arrangements, and of deliberate collaboration, the more akin to open innovation the designed processes are. The collaborations may be based on joint R\&D and/or marketing activities with actors outside the boundaries of the individual firm. The result is an information exchange, i.e. simultaneous inbound and outbound knowledge flows. If, in contrast, the open innovation process of an organization draws mainly on inbound knowledge flows, outside actors providing the knowledge must be compensated in exchange by, e.g., getting access to improved customized products and services as in the case of customer co-creation activities. Or the outside actors are directly financially compensated, e.g., through research grants or contract research.

In any case, it is important to recognize that there are constraints on the deliberate acquisition and exchange of knowledge which set limits to the openness of innovation processes. A first constraint lies in the absorptive capacity of the potential knowledge recipients ((Cohen and Levinthal 1989), see also (Witt and Zellner 2009)) for an extended discussion). A second constraint is the capacity of the channels by which specific knowledge can be acquired. With insufficient or lacking channels, the tapping of outside knowledge for creative recombinations is difficult if not impossible, and open innovation processes cannot develop their potential. For this reason, a platform offering efficient channels for gaining specific knowledge has always been a hallmark of innovative hotspots. For long time, expositions and industry fairs served as the main platform. Now the internet offers a channel of unprecedented capacity for acquiring knowledge at a global scale and at costs by orders of magnitude lower than ever before. 
It is not accidental, therefore, that the internet has been instrumental in boosting worldwide open innovation activities. The innovation process made significant headway, in particular, in the very material from which ICT and the internet itself is made, namely software. The reason is that software is based on a common language and logic that makes it easy for potential adopters to develop a common absorptive capacity. Moreover, electronic software can easily be transferred and collectively be shared. With the non-rivalry in use, software satisfies one of the conditions of a public good. The other condition - non-excludability - is satisfied for software developed in the open source movement. The fact that this is a public good and that it is nonetheless privately provided at an unprecedented scale may have come as a surprise. It, too, seems to be due to the specific conditions of the internet. With a broadly distributed absorptive capacity and an efficient knowledge exchange channel, individual users can contribute at a very low cost to them their own intellectual input to the open innovation process which is thus able to activate swarm intelligence for its progress.

The unique, previously unexperienced success of open source innovation processes in the internet has inspired some researchers to suggest these processes as a model for open innovations more generally (Chesbrough 2003). However, the broad openness of both inbound and outbound knowledge flows accomplished in this special innovation domain is not easily met in other innovation domains. The reason seems to be that open innovation processes, particularly those with open outbound knowledge flows, make it difficult to protect private knowledge from becoming a public good - which would not normally be privately provided. (Even in software development the lion's share of the products comes as closed innovations by commercial suppliers like Microsoft, Oracle, SAP which enforce the excludability condition of private intellectual property.) A recent empirical study of a sample of large firms from diverse industries in the U.S. and in Germany (Chesbrough and Brunswicker 2013) indeed shows that, when it comes to opening innovation processes to outside actors, these actors are usually still few and in geographically close vicinity. Inbound knowledge flows in the context of innovative activities are mostly restricted to the firms' customers and purveyors and to university contacts. Outbound information flows take place by selling products which embody specific technological knowledge to customers, by joint ventures with few partners, and by collective standardization processes in the industry.

Ultimately, a motivational conflict becomes apparent here which implies yet another constraint on the openness of innovation processes. This constraint relates to the second of the mentioned main research themes, i.e. the explanation of the motivation of innovators. Pursuing innovative activities usually involves substantial investments of human and financial resources. The returns on these investments are more uncertain than investments in already established businesses because of lack of precedents and the epistemic bounds. The motivation for taking the risks of such uncertain investments rests in the expectation that a competitive advantage can be gained that results in an innovation rent. ${ }^{2}$ This means a profitability of the investment which is higher than that of non-innovative investments. However, if an innovation rent is indeed feasible, it will only last as long as potential competitors can be excluded from competing it away by imitating the innovation. Precisely this condition may conflict with the openness of an innovation process. The disclosure of internal knowledge to outside actors carries the risk that this knowledge becomes a public good. The more open outbound 
knowledge flows are, the easier innovative know-how can be acquired by potential competitors and the hoped-for innovation rent or even the entire profit may be dissipated. $^{3}$

With respect to the strategic decision of choosing an open or a closed innovation strategy, the simple question therefore is: If the motivation is to gain a competitive advantage and an innovation rent, are inbound and/or outbound knowledge flows necessary for making the innovation feasible? And to what extent do these flows affect the profitability of the venture? The fact that outside the internet-based open source movement this question addresses a real problem is reflected in the findings of Chesbrough and Brunswicker (2013). In their empirical study, inbound open innovation practices are almost four times more frequent in the firms they sampled than outbound activities. When outbound activities are undertaken at all, they typically take place within purveyor-customer relationships where customers are specialized in different markets and/or stages of the value chain and, hence, unlikely to become direct competitors. Or the activities are based on contractual arrangements that are designed to create and sanction a coalition of innovating members who share the costs of generating innovative knowledge and gain access to it on a mutual basis such as in joint ventures or bodies for industrial standardization.

\section{The effects of innovations: private gains vs. social costs}

In view of the positive effects of innovations it is not surprising that in politics and in the public the call for more innovative efforts abounds. Innovations bring relief from physically exhausting work, drive up labor productivity, enable per capita income growth, yield competitive advantages both nationally and internationally, create new employment opportunities, result in new goods and services - in short: have improved the human lot dramatically as compared to one or two centuries ago. Works on the effects of innovations (the third of the mentioned major research themes) - certainly almost all of the neo-Schumpeterian contributions - highlight more or less exclusively these positive effects of innovative activities. Likewise, the management literature propagates innovations as prime strategy for gaining a competitive advantage and generating sustained profits.

However, a portrayal of the effects of innovations would be incomplete if it would not realize that there is also a dark side related to many innovations, and that for this reason it must be asked what kind of innovations we need to secure our future. Despite the fact that innovations have been highly successful in the market and generated substantial profits, it has not been uncommon that some of them ended up in a disaster. A treacherous feature of innovations is that they can "bite back" (see (Tenner 1996)). Due to the epistemic bounds on fully recognizing the implications of innovations, the negative effects often only turn out with a considerable time delay. Adopters of the innovation who realize them as diluting their contractual situation may exercise a right of recourse and induce others not to buy the innovation. The private gains which both the innovator and the adopter expected to obtain then disappear and so does the innovation.

While in this case the negative effects are internalized and the self-regulation of the market works, in the case of negative externalities the adopters' contractual position is not directly affected. Therefore they are unlikely to react in a similar way and to force the innovator via the market to internalize the costs she causes to others. One sort of 
such externalities are "pecuniary" ones which hit the innovator's competitors with the traditional - now substituted - products and services and/or their outdated technologies and resources. Specific investments which the competitors made before the innovation was introduced are devalued or even lost. Capital owners face losses on their expected returns, labor faces losses on the expected income from human capital investments.

A topical example are the effects which highly innovative industries such as consumer electronics have on traditional manufacturing industries particularly in highly developed countries like the U.S. Attracted by the innovations, consumers increasingly spend on smart phones, say, while expenditures on, e.g.,, household supplies, linen, upholstery grow much less, if at all. The effects of the innovation induced substitution are completely mediated by the price mechanism and result in a redistribution of income increases, if not of absolute income. In this particular case, it also amounts to an international redistribution of income increments often associated with "globalization". Since the highly innovative consumer electronics industry has substantial parts of its value chain located in Asia, it contributes to new employment opportunities and rising income there. In contrast, traditional industries in the U.S. suffer from the substitution competition which causes losses of employment and contributes to stagnating labor income here.

Nonetheless, in the case of such "pecuniary" external effects, the sum of private gains from a successful innovation usually exceeds the sum of private losses for the (world) economy as a whole. In principle, those who suffer losses as a result of the innovation could therefore be compensated out of society's innovation gains. If this were to happen, the compensations would amount to an internalization of the "pecuniary" externalities and a net welfare gain from realizing the innovation could be stated. ${ }^{4}$ In contrast, in the case of negative technological externalities, there are not only more or less dramatic redistribution effects. The entire society may turn out to be forced to bear heavy social costs caused by innovations. These social costs can exceed the sum of private gains obtained through the innovation, the more so the later the negative effects are discovered. In such cases, society can suffer a net welfare loss from innovations. Despite the fact that such innovations have successfully passed the market test, they are the opposite of what we need to secure our future. Unfortunately, this is not a rare case.

For instance - to mention some spectacular cases - in the 1960s chlorofluorocarbon gas was successfully marketed as a major chemical innovation in the production of cooling agent, fire-extinguishing agents, multi-purpose lubricants, aerosol such as in hair sprays, and many other purposes. It seemed to solve many technical problems in an inexpensive and convenient way. Only years later it was discovered what immense social costs the innovation caused. Chlorofluorocarbon emissions contribute significantly to the greenhouse effect. Moreover, the gas accumulated in the stratosphere and started to destroy the Earth's ozone layer. After the discovery a cumbersome process of reaching an agreement on collectively putting a ban on chlorofluorocarbon gas use started. While the process was eventually successful it may last long until the ozone layer fully recovers. Further examples of innovations passing the market test as supposed solutions for technical or commercial problems which later turned out to cause immense social costs are not difficult to find: new materials such as asbestos; new 
pesticides such as DDT; new drugs such as Rofecoxib (Vioxx); new techniques such as nuclear power generation or deep sea oil drilling, and so on (see also (Tenner 1996)).

In these cases, the unexpected negative externalities are a result of innovative production techniques or the particular features of new products. Since the epistemic bounds prevent an immediate identification of all implications of an innovation the risk that innovations develop such negative externalities can never be excluded. All that can be hoped for is that by proper arrangements for the innovation process the chances of identifying innovations causing serious externalities as early as possible are increased. It is at this point that the open vs. closed innovation option comes in as the discussion in the next section will show.

\section{The role of opening the innovation process}

When organizations, particularly commercial firms, consider starting an innovation project, the new cognitive concepts that inform the imagined new business are still tentative and incomplete. Accordingly, beliefs in whether the project will become a success or failure are not yet consolidated. In the team responsible for pursuing the innovation, typically consisting of developers, engineers and scientifically trained staff, marketing specialist, and managers with entrepreneurial function, not everyone is necessarily convinced of a successful outcome. Opinions on this question are formed, pro and con, in an ongoing interaction between the involved team members processing newly gained information. Proponents and opponents of the project may develop second thoughts and change their respective opinion, depending on what argument or evidence is presented in their exchange. The discussed epistemic bounds notwithstanding, the credibility of the exchanged arguments is not entirely disconnected, of course, from already existing knowledge about the properties of the innovative project. However, the uncertainty about whether this knowledge is sufficiently representative of the unknown true feasibility and costs, not to forget social costs, of the innovation leave room for interpretative differences.

It is for these reasons that the teams responsible for an innovation project in an organization often open up the innovation process. They may mainly wish to consult outside expertise in the form of inbound knowledge flows as explained in Section 2. Such external opinions and advice are supposed to help improving, and sometimes result in modifications of, the understanding of the technical feasibility and the benefits and costs of the intended innovation. However, even when the consulting of external expertise is mainly organized in the form of inbound knowledge flows, some information about the innovation is likely to be disclosed in the exchange with the consulted outside actors. The more specific the information requested is, the more conclusive it may be for guessing what is going to be developed. Hence, an outbound information flow can only be prevented completely in a closed innovation process.

In effect, the consulting of external expertise adds weight to, and sometimes changes the weights of, the arguments exchanged within the innovating team. At the end of the day, opening up the innovation processes comes down to strengthening the not yet consolidated beliefs in either success or failure of the project within the innovating team. The question is whether, in comparison to closed innovation processes, open innovation activities also make a difference with respect to the likelihood of an earlier discovery of severe negative externalities of the considered innovation. 
The conditions under which this can be expected to be the case can be explored by means of a stylized model of the opinion formation process within the team which is responsible for the innovation project. The interactions underlying the opinion formation can result in a typical feature of a self-organizing process called phase transition in self-organization theory: An implicit bias in the assessment of the project can accumulate and eventually drive the process beyond a tipping point. The pro-innovation beliefs with which the project was started then turn into the conviction that the innovation is to be abandoned because of lacking success prospects or negative externalities. What has to be discussed here is the following. In case of severe negative externalities, is the tipping point more likely to be reached - implying a shorter expected waiting time for a transition - in open rather than in closed innovation processes?

For expository convenience let us assume a bi-modal framework in which the members of the team responsible in the organization for the innovation project either believe in the success of the innovation or in its failure. Hence, if the share of team members doubting the success - for brevity let us call them opponents - at time $t$ is denoted by $F(t)$, the share of team members believing in the success, the proponents, is $1-F(t)$. It can be assumed that an innovation project will only be started if (1$F(0)) \gg F(0)$. As a result of the exchange of arguments within the team, these beliefs can change so that opponent become proponents and vice versa.

In a probabilistic representation of the belief changes, switching from being proponent to becoming opponent can occur with probability $p(t)$ and the reverse switching from being opponent to becoming proponent with probability $q(t)$. A characteristic feature of opinion formation processes is the frequency-dependency of the switching probabilities, more specifically a nonlinear conformism effect: The more opponents there are in the team, i.e. the more members do not believe in a success of the innovation, the more than proportionately greater is the probability for proponents to become opponents, too. This implies a functional relationship $p(t)=\varphi(\mathrm{F}(\mathrm{t})), \varphi^{\prime}>0, \varphi^{\prime \prime}>0$. The conformism effect also works in the opposite case. Hence, the functional relationship for $q(t)=\phi(1-F(t)), \phi^{\prime}>0$, $\phi ”>0$. For the sake of the present argument it is sufficient to choose quadratic specifications for these functions with parameters $0<\alpha \leq 1$ and $0<\beta \leq 1$ so that

$$
p(t)=\alpha F(t)^{2}
$$

and

$$
q(t)=\beta(1-F(t))^{2}
$$

As has been said, due to the epistemic bound there is an irreducible ex ante uncertainty about the implications of the projected innovation. However, sooner or later these implications will gradually be revealed while the organization continues to pursue the innovation. The revealed information is likely to feed back on the interactive opinion formation process of the innovating team. In the model, the ongoing revelation process can therefore be assumed to result in a bias, however small, in the switching probabilities. Accordingly, there will be innovations for which the pieces of information revealed over time cast doubts on their success, especially when they give rise to fears that the innovation might develop severe negative externalities for which the innovating organization may at least in part be made liable. In the model this bias is represented by a ratio $\alpha / \beta>1$ for this kind of innovations and in the opposite case by $\alpha / \beta<1$. 
If the organization runs an open innovation process, the exchanges within the innovating team are complemented by a dialogue with external actors. The knowledge inflow from outside affects the opinion formation among the members of the innovating team. Hence, according to the motto "more eyes see better than few eyes", the bias expressed by the size of the ratio $\alpha / \beta$ should be strengthened the more so, the more external actors get involved in the open innovation, i.e. the more outside knowledge is obtained over time. Following this intuition, the external influence can be depicted by a variable

$$
x(t)=1-e^{-\kappa n(t)} .
$$

It depends on the (cumulative) number $n(t)$ of external actors getting involved in the team's opinion formation up to time $t$ and on a parameter $k>0$ reflecting the average strength of their influence. Now suppose the organization runs a completely closed innovation process. This means that $n(t)=0$ for all $t$. In that case $x(t)=0$. Put differently, the degree of openness of the innovation process is expressed in the model by the number $n(t)$. The more $n(t)$ grows over time, the more open the innovation process is and $x(t)$ approaches the value +1 more or less rapidly, depending on the parameter $k$.

On the basis of different values for $n(t)$ and, consequently $x(t)$, we can track how in the opinion formation process an innovation project - whether open or closed - fares over time. The critical variable is the share of opponents (or, conversely, proponents) of the project in the innovation team. By assumption, when the innovation project is initiated, $F(0)<1 / 2$. If the revealed information is positive, i.e. in case of $\alpha / \beta<0$, the share $F(t)$ is likely to decrease over time and the organization can be expected to continue pursuing the innovation. In the opposite case, $F(t)$ is increasing in the interactive opinion formation process until a strong majority or all of the innovation team become opponents and the project is abandoned.

Assuming that $t$ only takes integer values, the development of $F(t)$ is in the mean ${ }^{5}$ determined by the first order difference equation

$$
\begin{aligned}
& =0 \text { for } F(t)<0 \\
F(t+1) & =F(t)+(1-F(t)) p(t)(1+\gamma x(t))-F(t) q(t)(1-\gamma x(t)) \text { for } 0 \leq F(t) \leq 1, \\
& =1 \text { for } F(t)>1
\end{aligned}
$$

The factor $\gamma$ is determined by a sign function such that $\gamma=+1$ if $\frac{\alpha}{\beta}>1$ and $\gamma=-1$ if $\frac{\alpha}{\beta}<1$. This ensures that the bias in the switching probabilities is strengthened in the right direction. For $0 \leq F(t) \leq 1$ the second summand on the r.h.s. of Eq. (4) represents the mean "inflow" into the share of opponents, i.e. the switching from proponent to opponent, occurring at time $t$. The third summand gives the mean "outflow" from the share of opponents, i.e. the reverse switching. ${ }^{6}$

The question raised in the previous section was whether, in comparison to closed innovations, open innovation activities make a difference with respect to the time at which an innovation is stopped in case of severe negative externalities. Is an organization that has pushed the innovation the more likely to abandon the project that gradually turns out to be a failure or even disaster the more it relies on an open innovation process? To answer this question we have to explore the mean trajectory resulting from Eq. (4) for the specification $\frac{\alpha}{\beta}>1$ and, hence, $\gamma=+1$. $^{7}$ For expository convenience let us choose a simple numerical specification $\alpha=1$ and $\beta=1 / 2$ satisfying this condition. Inserting Eqs. (1), (2) and (3) into Eq. (4) and rearranging yields 


$$
F(t+1)=\frac{1+x(t)}{2} F(t)+2(F(t))^{2}-\frac{3+x(t)}{2}(F(t))^{3}
$$

subject to the condition $F(t+1)=0$ for $F(t)<0$ and $F(t+1)=1$ for $F(t)>0$.

The cubic difference Eq. (5) implies a bifurcation by which a tipping point emerges in the share of opponents, i.e. a critical mass or frequency $F^{c r i t}(t)$ of opponents. $F^{c r i t}(t)$ represents an unstable equilibrium point. Once $F(t)>F^{\text {crit }}(t)$ the mean process of Eq. (5) will over time be attracted to $F^{*}=1$. This is the all-opponent equilibrium which, by assumption, means that the innovation is abandoned. The question to be discussed can therefore be translated into whether and how the position of the tipping point varies in the interval $[0,1]$ with the openness of the organization's innovation activities. The answer can be given by analyzing the extreme cases of, on the one side, an entirely closed and, on the other side, a very open innovation process. In the former case, $n=0$ and, by Eq. (3), $x(t)=0$ while in the latter case a growing $n$ drives $x(t)$ close to 1 .

Let us start with an entirely closed innovation regime. For $x(t)=0$ Eq. (5) has three equilibrium points in the interval $[0,1]$ which can be found by setting $F(t+1)=F(t)$ and solving: $F^{*}=1$ which is stable, the instable equilibrium $F^{\text {crit }}=1 / 3$, and another stable equilibrium in $F^{*}=0$. Hence, there is the possibility that in a closed innovation regime, an innovating team starting with a share $F(0)<1 / 3$ is in a self-amplifying way attracted to an all-proponent equilibrium - despite the bias in the revealed information pointing to an impending failure. Only if the innovation project is from the very beginning controversial (i.e. $F(0)>1 / 3$ ) will the revealed information lead the innovating team to quickly refrain from continuing the innovation process.

A very different result obtains in very open innovation regimes. Consider he limiting case $x(t)=1$. In this case, Eq. (5) has two equilibrium points in the interval $[0,1]: F^{*}=$ 1 and $F^{\text {crit }}=0$. This means that $F(t)$ will (in the mean) be attracted to the only stable equilibrium $F^{*}=1$, in which everyone in the innovating team opposes the project, once the instable equilibrium $F^{\text {crit }}=0$, in which no one opposes, is left. Put differently, in an entirely open innovation process, one single member of the team opposing the innovation suffices to set in motion a development in which an innovation suspected of causing severe negative externalities is soon abandoned. Even if the bias expressed by the ratio $\frac{\alpha}{\beta}>1$ is very small $F(t)$ will then grow successively as a result of the conformism pressure building up through the external expertise influencing the opinion formation within the innovating team.

Since $F^{\text {crit }}$ varies parametrically with $n(t)$, a growing openness of the innovation process, i.e. $n(t)$ going from 0 to large values and $x(t)$ from 0 to 1 , implies a parametric shift of the tipping point $F^{\text {crit }}$ from the value $1 / 3$ (associated in the chosen numerical specification with $n(t)=0$ ) downwards to zero. Consequently, the share of opponents in the innovating team which suffices to drive $F(t)$ beyond $F^{\text {crit }}$ in the direction of $F^{*}=1$ becomes smaller and smaller and is therefore more likely to be reached. ${ }^{8}$

Thus, under the assumption of this model we obtain a clear result. The openness of the innovation process is crucial for reacting early to signs of a failure or even disaster threatening to follow from the pursuit of the innovation. The more open the innovation activity is, the more likely will an innovation be abandoned when there are hints pointing at a failure. In the interest of keeping social costs caused by negative externalities of innovations down it would therefore be desirable to have innovation processes that are 
as open as possible. As discussed in section 2, such openness may however conflict with the motivation of the innovating organization to protect the private knowledge on which its innovation is based from being diffused to competitors. To create this private innovative knowledge and to implement it in the form of a commercial business requires substantial investments. If the knowledge would diffuse, the innovation could easily be imitated by competitors and the expected innovation rent be quickly competed away.

There is thus a conflict of interests here. If openness of the innovation process would be made a legal requirement, potential innovators can be expected not to undertake many of the innovation projects they would be willing to start as closed activities. If, in contrast, choosing the degree of openness is left to the strategic discretion of the innovating organization, the choice is in most cases a more or less closed innovation activity. It can then happen that even disastrous innovations continue for long until rising social costs induce the public or the government to intervene and to force the innovating organization to let outside expertise in.

\section{Conclusions}

In a historical perspective, successful innovations have been the main drivers of economic growth creating wealth and raising the standard of living of the masses. Innovations are therefore often considered in a wholesale manner a desideratum in politics, in the public, and, not least, in innovation-related research. Such a view is warranted as long as innovations do not cause negative externalities that result in social costs outweighing the private gains. However, there are not only countless examples of innovations that failed and deprive those who pursued them of the resources they invested. There are also many cases in which innovations successfully passed the market test, but later turned out to have negative externalities that resulted in heavy social costs for society. Obviously, innovations of the latter kind do not secure our future but rather have the potential of threatening it.

In this paper it has therefore been explored by what arrangements concerning the innovation process in firms and other organizations the risk of an innovation ending up with excessive social costs can be kept down. As has been explained, the epistemic bounds on anticipating the implications of new technical and economic activities prevent an immediate solution. However, by means of a simple model exercise it has been shown that the internal reaction of firms and organizations in their innovating teams can differ dramatically with respect to how quickly an innovation developing signs of failure is stopped. The difference rests on how the knowledge flows related to an innovation are strategically shaped, namely in the fashion of open or closed innovation processes. Closed innovation regimes can fail to draw the right conclusions from the information successively revealed about the implications of an innovation. The more open the innovation process is, the more likely it is in contrast that an innovation be abandoned when there are hints pointing at a failure.

The answer to the question in the heading, of what kind of innovations we need to secure our future, would thus be that open innovations would be the desideratum. Yet, as has also been discussed at length in the present paper, an open arrangement of inbound and outbound knowledge flows - desirable in respect to an early discovery of negative externalities - confronts motivational limitations. Under an open innovation 
regime, innovating organizations may often be hindered to protect their investments from being imitated. If so, the expectation of earning an innovation rent would be destroyed and the motivation to pursue innovations be curbed. This motivational conflict points to a deeper issue. Requiring an opening up of innovation processes in order to reduce the risk of unanticipated social costs can be expected to result in less innovative activities being undertaken. Hence there is a trade-off between that risk on the one hand and the amount of innovative activities on the other. Put differently, society faces a trade-off in making its choice: The higher the pace of innovativeness which society wishes to have, the higher is also the inevitable risk of discovering potentially severe negative externalities too late. Open innovation processes with the capacity of resolving this dilemma do not seem to be in sight.

\section{Endnotes}

${ }^{1}$ In case of closed innovation processes, the trial and error knowledge revelation process may be pursued in the secluded atmosphere of a lab run by a innovating team, sometimes an entire R\&D department. Even in such a closed setting knowledge is acquired externally, albeit not on purpose related to a current innovation process, but on a wholesale basis by, e.g., hiring staff with practical or academic research experience, into a R\&D team. See Zellner (2003) for a case study of this form of knowledge acquisition.

${ }^{2}$ In some cases the motivation may also have to do with curiosity and stubbornness of pioneering explorers who are eager to unravel the consequences of their own ideas as Schumpeter (Schumpeter 1934) claimed.

${ }^{3}$ Open innovation processes are thus subject to incentive problems that have been postulated in the economic literature on innovations from the very beginning (see (Arrow 1962)). In a nutshell, the postulate says: if competitors cannot be excluded from innovative knowledge that is privately generated at a cost so that this knowledge becomes a public good, this knowledge is no longer, or not to a comparable, extent privately provided.

${ }^{4}$ In reality, however, notorious transaction costs prevent such compensations from taking place. The price of innovation-induced progress and growth resulting from what has been dubbed the "perennial gale of creative destruction" ((Schumpeter 1942), Chap. 7 ) is that gains and losses are distributed very unevenly across the economy.

${ }^{5}$ For the relationships between the mean process and the stochastic realization of single trajectories around the mean see the discussion in Weidlich (2000).

${ }^{6}$ The terms $1-F(t)$ and $F(t)$ in these summands represent the probability that the team member making a switch in $t$ with the corresponding biased probability is a proponent or an opponent of the innovation project, respectively.

${ }^{7}$ The case $\alpha / \beta<1$, i.e. an innovation turning out to be favorable, can be subjected to an analogous analysis which, however, is neglected here for space limitations.

${ }^{8}$ In the random realization of the stochastic switching process based on the individual probabilities $p(t)$ and $q(t)$ the actual increments of the share of opponents fluctuates around the mean increment given by Eq. (5). Consequently, the closer to 0 the tipping point $F^{\text {crit }}$ gets, the greater the chance that, by a cumulation of random fluctuations, $F(t)$ is pushed beyond $F^{\text {crit }}$ and the process is attracted to $F^{*}=1$. For a discussion of random realizations of such processes governed by a master equation see Weidlich (2000). 
Competing interests

The author declares that he has no competing interests.

Received: 23 June 2016 Accepted: 16 August 2016

Published online: 02 September 2016

\section{References}

Arrow, K. J. (1962). Economic welfare and the allocation of resources for invention. In R. R. Nelson (Ed.), The rate and direction of inventive activity (pp. 609-626). Princeton: Princeton University Press.

Chesbrough, H. W. (2003). Open innovation. the new imperative for creating and profiting from technology. Boston: Harvard Business School Press.

Chesbrough, H. W., \& Brunswicker, S. (2013). Managing open innovation in large firms. Survey report. Stuttgart: Fraunhofer.

Chesbrough, H. W., Vanhaverbeke, W., \& West, J. (Eds.). (2006). Open Innovation. Researching a New Paradigm. Oxford: Oxford University Press.

Cohen, W. M. (2010). Fifty years of empirical Studies of innovative activity and performance. In B. W. Hall \& N. Rosenberg (Eds.), Handbook of the economics of innovation (pp. 129-213). Amsterdam: Elsevier.

Cohen, W. M., \& Levinthal, D. A. (1989). Innovation and learning: the two faces of R\&D. Econ J, 99, 569-596.

Damanpour, F., \& Aravind, D. (2012). Managerial innovation: conceptions, processes, and antecedents. Manag Organ Rev, 8, 423-454.

Fagerberg, J., Srholec, M., \& Knell, M. (2007). The competitiveness of nations: why some countries prosper while others fall behind. World Dev, 35, 1595-1620.

Hanusch, H., \& Pyka, A. (Eds.). (2007). Elgar companion to neo-schumpeterian economics. Cheltenham: Edward Elgar. Kistermann, F. W. (1991). The invention and development of the hollerith punched card. IEEE Ann Hist Comput, 13(3), 245-259.

Metcalfe, J. S., Foster, J., \& Ramlogan, R. (2006). Adaptive economic growth. Camb J Econ, 30, 7-32.

Schumpeter, J. A. (1934). Theory of economic development. Cambridge: Harvard University Press.

Schumpeter, J. A. (1942). Capitalism, socialism and democracy. New York: Harper.

Tenner, E. (1996). Why things bite back - technology and the revenge of unintended consequences. New York: Knopf.

Weidlich, W. (2000). Sociodynamics - a systematic approach to mathematical modeling in the social sciences. Amsterdam: Harwood.

Witt, U. (2009). Propositions about novelty. J Econ Behav Organ, 70, 311-320.

Witt, U., \& Zellner, C. (2009). How firm organizations adapt to secure a sustained knowledge transfer. Econ Innov New Technol, 18(7), 647-661.

Zellner, C. (2003). The economic effects of basic research: evidence for embodied knowledge transfer via scientists' migration. Res Policy, 32(10), 1881-1895.

\section{Submit your manuscript to a SpringerOpen ${ }^{\circ}$ journal and benefit from:}

- Convenient online submission

Rigorous peer review

- Immediate publication on acceptance

- Open access: articles freely available online

- High visibility within the field

Retaining the copyright to your article

Submit your next manuscript at $\boldsymbol{~ s p r i n g e r o p e n . c o m ~}$ 